\title{
Notch signaling pathway promotes osteogenic differentiation of mesenchymal stem cells by enhancing BMP9/Smad signaling
}

\author{
JUNJIE CAO $^{1}$, YALIN WEI ${ }^{1}$, JING LIAN $^{1}$, LUNYUN YANG $^{1}$, XIAOYAN ZHANG $^{1}$, \\ JIAYING XIE $^{1}$, QIANG LIU ${ }^{1}$, JINYONG LUO ${ }^{1}$, BAICHENG HE ${ }^{2}$ and MIN TANG ${ }^{1}$ \\ ${ }^{1}$ Key Laboratory of Diagnostic Medicine Designated by the Chinese Ministry of Education, Chongqing Medical University; \\ ${ }^{2}$ Department of Pharmacology, School of Pharmacy, Chongqing Medical University, Chongqing 400016, P.R. China
}

Received August 17, 2016; Accepted April 26, 2017

DOI: $10.3892 /$ ijmm.2017.3037

\begin{abstract}
Notch is an important pathway in that it regulates cell-to-cell signal transduction, which plays an essential role in skeletal remodeling. Bone morphogenetic protein (BMP)9 has been regarded as one of the most efficient BMPs by which to induce osteogenic differentiation in mesenchymal stem cells (MSCs). Understanding the interaction between Notch and BMP9 signaling is a critical issue for optimizing the application of MSCs and BMPs in bone tissue engineering. In the present study, we investigated the role of Notch signaling in the BMP9-induced osteogenic differentiation of MSCs. Our data demonstrated that Notch signaling obviously enhanced BMP9-induced osteogenic differentiation in MSCs in vitro and in vivo. Notch signaling augmented the activity of BMP9-induced BMP/Smad signaling and increased the gene expression of essential osteogenic factors induced by BMP9 in MSCs, such as runt-related transcription factor 2 (Runx2), type I collagen (Colla1) and inhibitor of differentiation (Id)1. We also found that Notch signaling promoted the expression of activin-like kinase 2 (ALK2) induced by BMP9, and the inhibitory effect of dnALK2 on BMP9-induced osteogenic differentiation was rescued by constitutive overexpression of Delta-like 1 (DLL1). Notch signaling also exhibited an apparent effect on the proliferation of mouse embryo fibroblasts (MEFs) during BMP9-induced osteogenic differentiation. These results indicate that Notch plays a significant role in mediating BMP9-induced osteogenic differentiation in MSCs, which may be partly regulated by upregulation of the expression of ALK2.
\end{abstract}

Correspondence to: Dr Min Tang, Key Laboratory of Diagnostic Medicine Designated by the Chinese Ministry of Education, Chongqing Medical University, 1 Yixueyuan Road, Yuzhong, Chongqing 400016, P.R. China

E-mail: catom@126.com

Key words: bone morphogenetic protein 9, Notch signaling, mesenchymal stem cells, activin-like kinase 2, osteogenic differentiation

\section{Introduction}

Notch is a signaling pathway which regulates cell-to-cell signal transduction. Notch was thus named as its inactivation caused notches in the wing blade of Drosophila melanogaster (1,2). In mammals, the canonical Notch signaling is mainly composed of five Notch ligands [Jagged1 and 2, and Delta-like (DLL)1, 3 and 4] and four Notch receptors (Notch1-4) (3,4). Notch signaling is initiated when Notch ligands bind with the receptors, then the Notch intracellular domain (NICD) is cleaved and released, followed by translocation from the cellular membrane to the nucleus (5). In the nucleus, the NICD binds with the transcriptional regulator of the CSL family to regulate downstream targets (6). The CSL family includes $\mathrm{C}$ promoter binding factor-1 (CBF-1) in mammals, also known as recombination signal-binding protein for immunoglobulin $\mathrm{J}_{\kappa}$ region $\left(\mathrm{RBP}-\mathrm{J}_{\kappa}\right)$ in mice, Suppressor of Hairless [Su(H)] in Drosophila and longevity assurance gene 1 (Lag1) in Caenorhabditis (7). Notch signaling is important for cell fate, proliferation, apoptosis and cell migration (8-12). Recent research has demonstrated that Notch signaling also plays an important role in skeletal remodeling (13-15).

Bone morphogenetic proteins (BMPs) are members of the transforming growth factor- $\beta$ (TGF- $\beta$ ) superfamily, and more than 20 BMP members have been identified $(16,17)$. Mammalian BMP receptors include seven type I receptors, which are activin-like kinase (ALK)1-7 and five type II receptors, which include ActRIIA, ActRIIB, BMPRII, T $\beta$ RII, and AMHRII. BMP signaling is activated when BMPs bind with type II receptors, and then type I receptor is rescuited and phosphorylated, which activates the receptor Smad (R-Smad) protein. In the cytoplasm, R-Smad binds to co-Smad (Smad4) and translocates into the nucleus to regulate the expression of target genes (18-20). BMPs have a broad spectrum of biological functions, such as the regulation of cell proliferation and differentiation during development (21-23). In addition, some BMPs have been used in bone tissue engineering for various bone-associated diseases (24-26). Yet, the mechanism underlying these processes remains unclear. A thorough analysis of the osteogenic activity of 14 human BMPs has been made and found that BMP9 is the most efficient BMP in inducing the osteogenic differentiation of MSCs both in vitro and in vivo (27-29). BMP9, also called growth differentiation factor-2 (GDF-2), was discovered and isolated from 
a liver cDNA library of embryonic mice. Its precursor protein shares 50-55\% amino acid sequence identity with BMP2, 4, 5, 6 and 7. The homology of BMP9 between the human and the mouse is $\sim 80 \%$ (30-33).

As mentioned above, Notch and BMP signaling have a similar mode of function, and are both involved in regulating cell fate and proliferation during development. Recently, research has confirmed that Notch signaling interacts with the TGF- $\beta$ pathway to regulate cell growth and myogenic differentiation (34-38). Yet, it remains unclear whether Notch crosstalks with BMP9 in bone formation.

In the present study, we investigated the possible role of Notch signaling in BMP9-induced osteogenic differentiation in MSCs. Our results showed that the Notch pathway significantly promoted BMP9-induced osteogenic differentiation and proliferation of MSCs, which may be mediated by the upregulation of ALK2

\section{Materials and methods}

Cell culture. C3H10T1/2 and C2C12 cells were purchased from the American Type Culture Collection (ATCC, Manassas, VA, USA) and cultured in complete Dulbecco's modified Eagle's medium (DMEM) (HyClone, Logan, UT, USA) supplemented with $10 \%$ fetal bovine serum (FBS) (Gibco, Grand Island, NY, USA), $100 \mathrm{U} / \mathrm{ml}$ of penicillin and $100 \mu \mathrm{g} / \mathrm{ml}$ of streptomycin. Cells were incubated at $37^{\circ} \mathrm{C}$ in $5 \% \mathrm{CO}_{2}$. Mouse embryo fibroblasts (MEFs) were isolated from post coitus day 12.5 mice ( 5 female and 5 male mice, purchased from Beijing Institute of Chinese Medicine), as described previously (39).

Reagents and antibodies. p-Smad1/5/8 (cat. no. 9516) was purchased from Cell Signaling Technology, Inc. (Danvers, MA, USA) and Smad1/5/8 (cat. no. sc-6031-R) was purchased from Santa Cruz Biotechnology, Inc. (Santa Cruz, CA, USA). Glyceraldehyde-3-phosphate dehydrogenase (GAPDH; cat. no. TA-08) and $\beta$-actin (cat. no. TA-09) were purchased from Zhongshan Golden Bridge Biotechnology (Beijing, China). $\gamma$-secretase inhibitor DAPT was purchased from Sigma-Aldrich (St. Louis, MO, USA), dissolved in dimethyl sulfoxide (DMSO) and stored at $-80^{\circ} \mathrm{C}$. The recombinant adenoviruses including Ad-BMP9, Ad-DLL1, Ad-dnNotch1, Ad-dnALK1, Ad-dnALK2, Ad-GFP and Ad-RFP were kindly provided by Dr Tong-Chuan He (University of Chicago Medical Center, Chicago, IL, USA).

RNA extraction, reverse transcription $(R T)$, polymerase chain reaction $(P C R)$ and quantitative $P C R(q P C R)$. Total RNA was extracted from the cells with TRIzol reagents (Takara, Otsu, Japan), and was reverse transcribed to cDNA using the Takara PrimeScript RT reagent kit. Semi-quantitative RT-PCR was performed as described previously $(40,41)$. The cDNA products were further diluted 5- to 10-fold and used in the successive experiments. A touchdown cycling program was used as follows: $94^{\circ} \mathrm{C}$ for $5 \mathrm{~min}, 94^{\circ} \mathrm{C}$ for $30 \mathrm{sec}, 68^{\circ} \mathrm{C}$ for $30 \mathrm{sec}$, and $72^{\circ} \mathrm{C}$ for 12 cycles with a decrease in $1^{\circ} \mathrm{C} /$ cycle; then, $94^{\circ} \mathrm{C}$ for $30 \mathrm{sec}, 55^{\circ} \mathrm{C}$ for $30 \mathrm{sec}$, and $72^{\circ} \mathrm{C}$ for $30 \mathrm{sec}$ for $18-27$ cycles depending on the abundance of the target genes. The PCR products were resolved on $2 \%$ agarose gels. All samples were normalized with the expression level of mouse GAPDH.
qPCR analysis was performed using a SYBR Premix Ex Taq kit (Takara). The cycling program consisted of $94^{\circ} \mathrm{C}$ for $2 \mathrm{~min}$ and $30 \mathrm{cycles}$ at $92^{\circ} \mathrm{C}$ for $20 \mathrm{sec}, 57^{\circ} \mathrm{C}$ for $30 \mathrm{sec}$, and $72^{\circ} \mathrm{C}$ for $20 \mathrm{sec}$, followed by a plate read at $78^{\circ} \mathrm{C}$ for each cycle. All samples were evaluated in triplicate and normalized to GAPDH. The primer pairs of target genes are presented in Table I.

Preparation of conditioned medium. BMP9-conditioned medium (BMP9-CM) was prepared as described previously (42). Briefly, subconfluent HCT116 cells (in a $75 \mathrm{~cm}^{2}$ flask) were infected with an optimal titer of Ad-BMP9 or Ad-GFP control. At $4 \mathrm{~h}$ after treatment, the medium was replaced with serum-free DMEM. The conditioned medium was collected at $48 \mathrm{~h}$ after infection and used as soon as possible.

Alkaline phosphatase (ALP) assays. ALP activity was analyzed by a modified Great EscAPe SEAP chemiluminescence kit (Takara). Each assay condition was performed in triplicate, and the results were repeated in three independent experiments. ALP activity was normalized by the total cellular protein concentrations among the samples.

Matrix mineralization assay (Alizarin Red S staining). Cultured cells were seeded in 24-well cell culture plates and infected with Ad-DLL1 followed by treatment with BMP9-CM, ascorbic acid $(50 \mathrm{mg} / \mathrm{ml})$ and $\beta$-glycerophosphate $(10 \mathrm{mM})$. On day 11 , the mineralized matrix nodules were stained for calcium precipitation by means of Alizarin Red S staining, as described previously (41). Briefly, the cells were fixed with $0.05 \%(\mathrm{v} / \mathrm{v})$ glutaraldehyde at room temperature for $10 \mathrm{~min}$. After being washed with double-distilled water, the fixed cells were incubated with $0.4 \%$ Alizarin Red S (Sigma-Aldrich) for $5 \mathrm{~min}$, followed by extensive washing with double-distilled water. The staining of calcium mineral deposits was recorded under a microscope.

Western blot analysis. The cells were seeded in $75-\mathrm{cm}^{2}$ cell culture dishes and subjected to the indicated treatments. At the indicated time-points, the cells were harvested and washed with cold phosphate-buffered saline (PBS) and extracted in protein buffer (20 mM Tris, $\mathrm{pH} 7.4,150 \mathrm{mM} \mathrm{NaCl}, 1 \% \mathrm{P} 40$, and $1 \mathrm{mM}$ EDTA) in the presence of protease and phosphatase inhibitors. Proteins were fractionated by sodium dodecyl sulfate-polyacrylamide gel electrophoresis (SDS-PAGE). Following electrophoretic separation, the proteins were transferred onto a PVDF membrane. The membrane was blocked with $5 \%$ bovine serum albumin (BSA) for $2 \mathrm{~h}$ at $37^{\circ} \mathrm{C}$ and probed with the primary antibody (diluted $1: 1,000$ ) overnight at $4^{\circ} \mathrm{C}$, then washed three times with Tris-buffered saline contained $0.1 \%$ Tween-20 (TBST). The membrane was then incubated with horseradish peroxidase-conjugated goat anti-rabbit (cat. no. ZB-2301) or goat anti-mouse (cat. no. ZB-2305) secondary antibodies (diluted 1:5,000; Zhongshan Golden Bridge Biotechnology). Finally, the membrane was exposed with ECL (Thermo Fisher Scientific, Inc., Rockford, IL, USA).

Transfection and luciferase reporter assay. The cells were transfected with $2 \mu \mathrm{g}$ per flask of BMPR-Smad-binding element luciferase reporter (p12xSBE-Luc) using Lipofectamine 
Table I. Primer sequences.

\begin{tabular}{lll}
\hline Gene & \multicolumn{1}{c}{ Forward primer $\left(5^{\prime} \rightarrow 3^{\prime}\right)$} & \multicolumn{1}{c}{ Reverse primer $\left(5^{\prime} \rightarrow 3^{\prime}\right)^{\prime}$} \\
\hline DLL1 & CCGGCTGAAGCTACAGAAAC & AGCCCCAATGATGCTAACAG \\
dnNotch1 & GCAGAACAACAAGGAGGAGACT & GAGGTCCTTAGCTTCCTTGCTAC \\
Hey 1 & GGCCTGCTTGGCTTTTCT & CCAAGTGCAGGCAAGGTC \\
Runx2 & GGTGAAACTCTTGCCTCGTC & AGTCCCAACTTCCTGTGCT \\
OCN 1 C & CGGCTCCTGCTCCTCTTA & TTCATTGCATTGCACGTCAT \\
OPN & TCTGACAAAGCCTTCATGTCC & AAATAGTGATACCGTAGATGC \\
Id 1 & ACACTTTCACTCCAATCGTCC & TGCCCTTTCCGTTGTTGTCC \\
Id2 & ACGACATGAACGGCTGCT & CAGCTGCAGGTCCCTGAT \\
Id3 & CAGCATCCCCCAGAACAA & TCTGGTGATGCAGGCTGA \\
ALK1 & CTACGAGGCGGTGTGCTG & GCGCGAGTAGCAGTGGTT \\
ALK2 & ACCTGGGACTGGCTGTGA & GCAGTCTGTGCGGATGTG \\
GAPDH & GTGGCTCCGGTCTTCCTT & AGCGACATTTTCGCCTTG \\
\hline
\end{tabular}

DLL, Delta-like; dnNotch1, dominant-negative mutant of Notch1; Runx2, runt-related transcription factor 2; Colla1, type I collagen; OCN, osteocalcin; OPN, osteopontin; Id, inhibitor of differentiation; ALK, activin-like kinase.

2000 (Invitrogen Corp., Carlsbad, CA, USA). At 24 h after transfection, the cells were replated in 24-well plates and treated with BMP9-CM and/or Ad-DLL1, Ad-dnNotch1, DAPT. At $36 \mathrm{~h}$ after treatment, the cells were lysed and harvested for luciferase assays using the Luciferase Assay kit (Promega Corp., Madison, WI, USA). Each assay condition was performed in triplicate. The results were repeated in at least three independent experiments. Luciferase activity was normalized with the total cellular protein concentrations among the samples.

Stem cell implantation and ectopic ossification. MEFs were co-infected with Ad-BMP9 and/or Ad-DLL1, Ad-dnNotch1 for $24 \mathrm{~h}$, and harvested for subcutaneous injection $\left(5 \times 10^{6}\right.$ cells per injection) into the flanks of athymic nude (nu/nu) mice (4- to 6-week-old male Sprague-Dawley). At 4 week(s) after treatment, the animals were euthanized, and the bony masses were collected for micro-CT imaging and histologic evaluation. All animal experiments were approved by the Ethics Committee of Chongqing Medical University.

Micro-CT imaging analysis, hematoxylin and eosin $(H \& E)$ and Masson's trichrome staining. Animals were euthanized at 4 week(s) and bony masses were imaged using high-performance micro-CT imager component of a GE Triumph (GE Healthcare, Piscataway, NJ, USA) trimodality preclinical imaging system. All image data analysis was performed using Amira 5.3 (Visage Imaging, Inc., San Diego, CA, USA).

Retrieved tissues were fixed in $10 \%$ neutral-buffered formalin overnight and processed for paraffin embedding. Serial sections of the embedded tissues were stained with H\&E and Masson's trichrome staining as previously described (43).

Flow cytometric (FCM) assay. Cells were seeded in 6-well plates and harvested after a 72-h treatment, washed with PBS three times and fixed with $75 \%$ iced-ethanol at $4^{\circ} \mathrm{C}$. The fixed cells were washed with PBS and stained with propidium iodide-containing RNase followed by fluorescence-activated cell sorting for cell cycle analysis.

Statistical analysis. Data are reported as the means \pm SD. Statistical analysis was conducted using SPSS software version 14 (SPSS, Inc., Chicago, IL, USA). P<0.05 was considered as statistically significant.

\section{Results}

Effects of Notch signaling on BMP9-induced early osteogenic differentiation in MSCs. We sought toexplore whether or not Notch signaling has any effect on a BMP9-induced early osteogenic marker. We first adopted DAPT, an inhibitor of the $\gamma$-secretase complex, to inhibit the Notch activity of MSCs. We also confirmed that Ad-DLL1 upregulated the level of DLL1 in MEFs, and the dominant-negative mutant of Notch1 (dnNotch1) which contains extracellular and transmembrane domains but lacks cytoplasmic domains was highly expressed in the Ad-dnNotch1-infected cells (data not shown). We used Ad-dnNotch1 and Ad-DLL1 to downregulate and upregulate Notch signaling, respectively (data not shown). Moreover, by using ALP staining and activity assay, we found that BMP9-induced ALP activity was significantly inhibited by DAPT and Ad-dnNotch1 in a concentration-dependent manner (Fig. 1A, B and D). Conversely, Ad-DLL1 enhanced BMP9-induced ALP activity (Fig. 1C). These data suggested that Notch signaling enhances the BMP9-induced early osteogenic differentiation of MSCs.

Effects of Notch signaling on BMP9-induced late osteogenic differentiation in MSCs. Although ALP is a well-established early osteogenic marker, it may not be an accurate predictor of the late stage of osteogenic differentiation and bone formation (41). Thus, we aimed to determine whether Notch signaling has an effect on the expression of BMP9-induced 

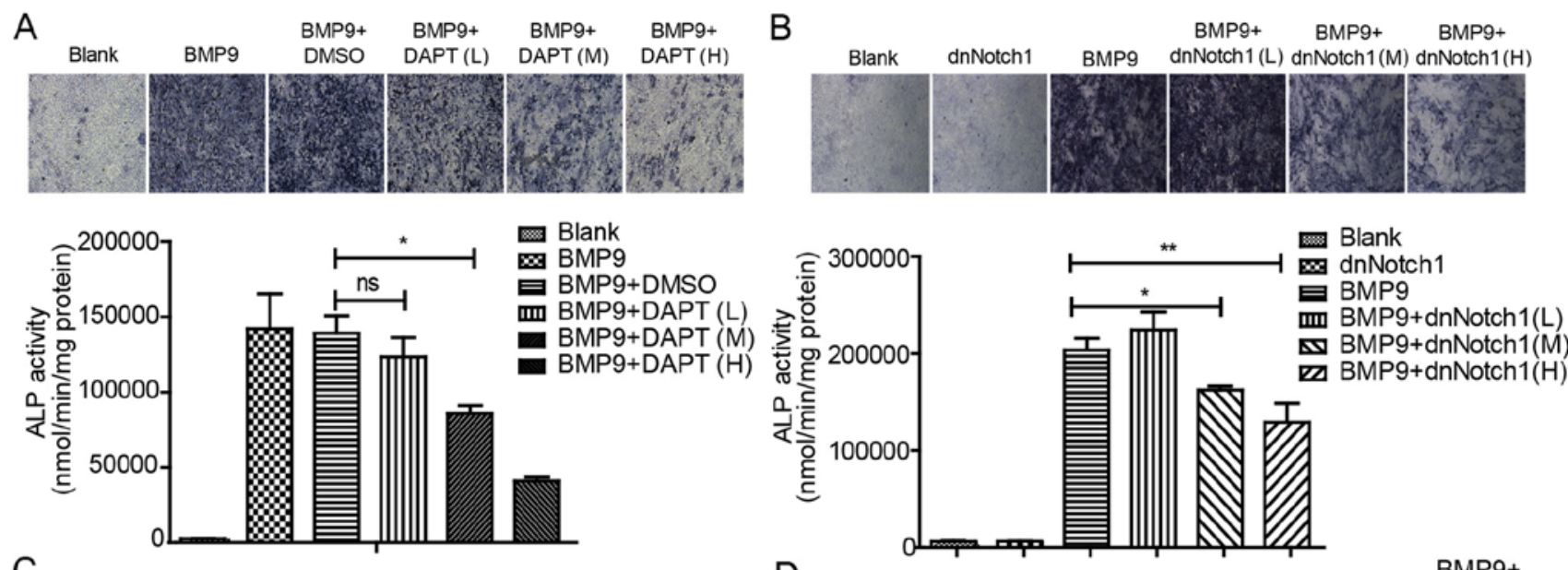

C

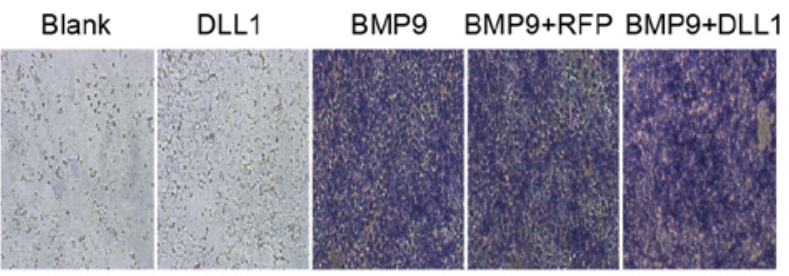

Blank RFP dnNotch1 BMP9 BMP9+RFP dnNotch1
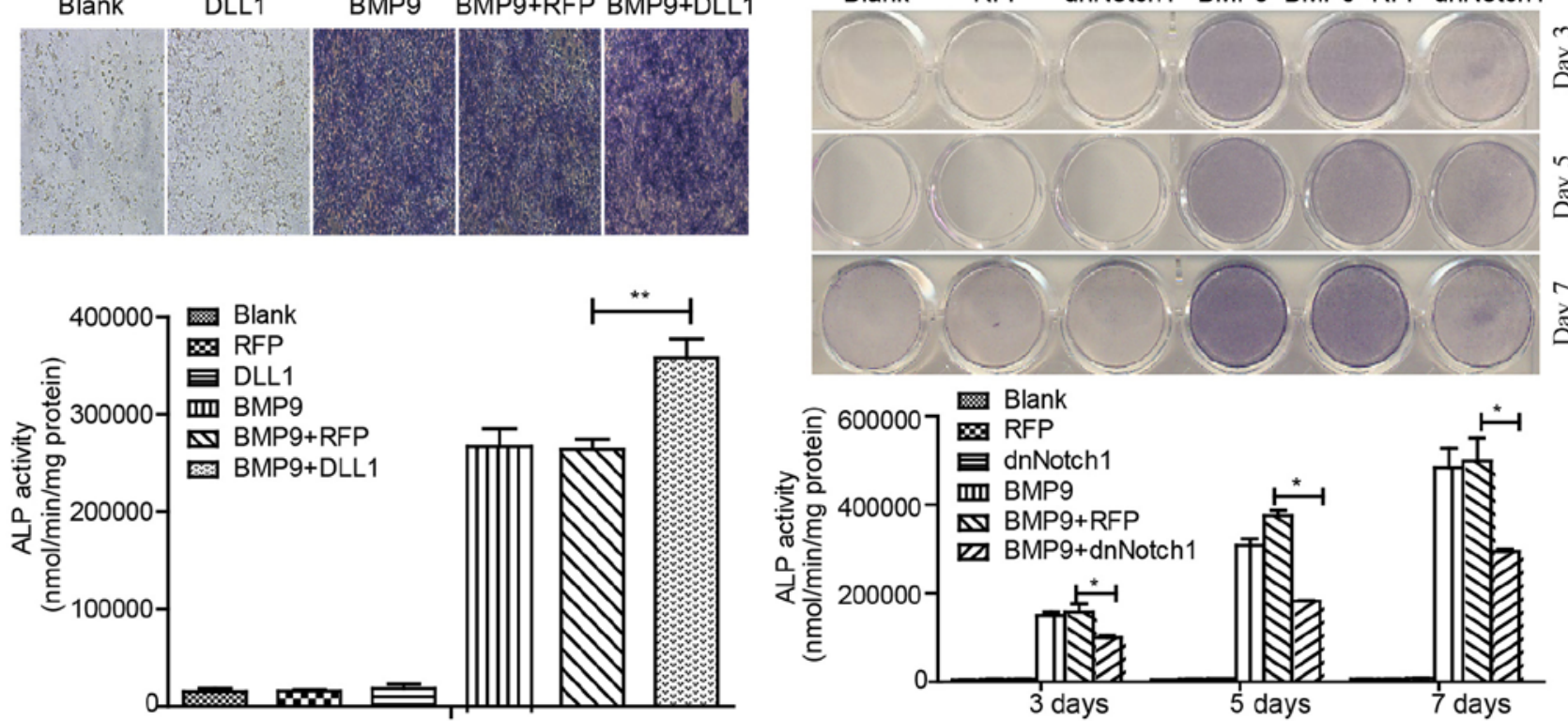

Figure 1. Notch signaling enhances BMP9-induced early osteogenic differentiation of MSCs. (A) MEFs were treated with Ad-BMP9 in the presence of various concentrations of DAPT ( $\mathrm{L}=5 \mu \mathrm{M}, \mathrm{M}=10 \mu \mathrm{M}$ and $\mathrm{H}=15 \mu \mathrm{M})$, and the BMP9-induced ALP activity was assessed by quantitative assay and staining assay at 7 day(s) post-treatment. (B) MEFs were infected with various titers of Ad-dnNotch1, followed by treatment with BMP9-CM, ALP activity was measured by quantitative assay and staining assay at 5 day(s) post-treatment. (C) MEFs were exposed to Ad-RFP or Ad-DLL1 in the presence of BMP9-CM, and the BMP9-induced ALP activity was assessed by quantitative assay and staining assay at 7 day(s) post-treatment. (D) MEFs were treated with BMP9-CM and/or Ad-dnNotch1, and the ALP activity was measured by quantitative assay and staining assay at 3,5,7 day(s) post-treatment. Magnification, x100. ${ }^{*} \mathrm{P}<0.05,{ }^{* *} \mathrm{P}<0.01$. ns, no statistical significance; BMP, bone morphogenetic protein; MEFs, mouse embryo fibroblasts; ALP, alkaline phosphatase; dnNotch1, dominant-negative mutant of Notch1; BMP9-CM, BMP9-conditioned media; DLL, Delta-like.

late osteogenic markers, such as osteopontin (OPN) and osteocalcin $(\mathrm{OCN})$. By RT-PCR or Alizarin Red S staining, we found that the combination of Ad-BMP9 and DAPT treatment significantly decreased the expression of OCN in a concentration-dependent manner (Fig. 2A); The expression of OCN and OPN decreased when treated with Ad-dnNotch1 (Fig. 2B). Conversely, Ad-DLL1 treatment was found to enhance the matrix mineralization induced by BMP9 (Fig. 2C). These data suggested that Notch signaling facilitates BMP9-induced late osteogenic differentiation in MSCs.

Effects of Notch signaling on BMP9-induced ectopic ossification. Our in vitro data revealed that Notch signaling plays an important role in BMP9-induced osteogenic differentiation of MSCs. Thus, we determined the effect of Notch on BMP9-induced ectopic bone formation. The infected MEFs were collected and injected subcutaneously into athymic nude mice. After 4 week(s), the animals were sacrificed and the bony masses were retrieved (Fig. 3A). The overall sizes of bony masses from the Ad-BMP9 combined with Ad-DLL1 group were apparently larger than that from the Ad-BMP9 group, and the bony masses from the group treated with Ad-BMP9 and Ad-dnNotch1 were significantly smaller than that of the Ad-BMP9 group. Histologic analysis indicated that, compared with the Ad-BMP9 group, the trabecular bone and osteoid matrix area was obviously increased in the group of Ad-BMP9 combined with Ad-DLL1, and was significantly decreased in the Ad-BMP9 combined with Ad-dnNotch1 group (Fig. 3B). Micro-CT scanning analysis showed the same results (Fig. 3C). These data demonstrated that Notch signaling enhances BMP9-induced ectopic bone formation. 


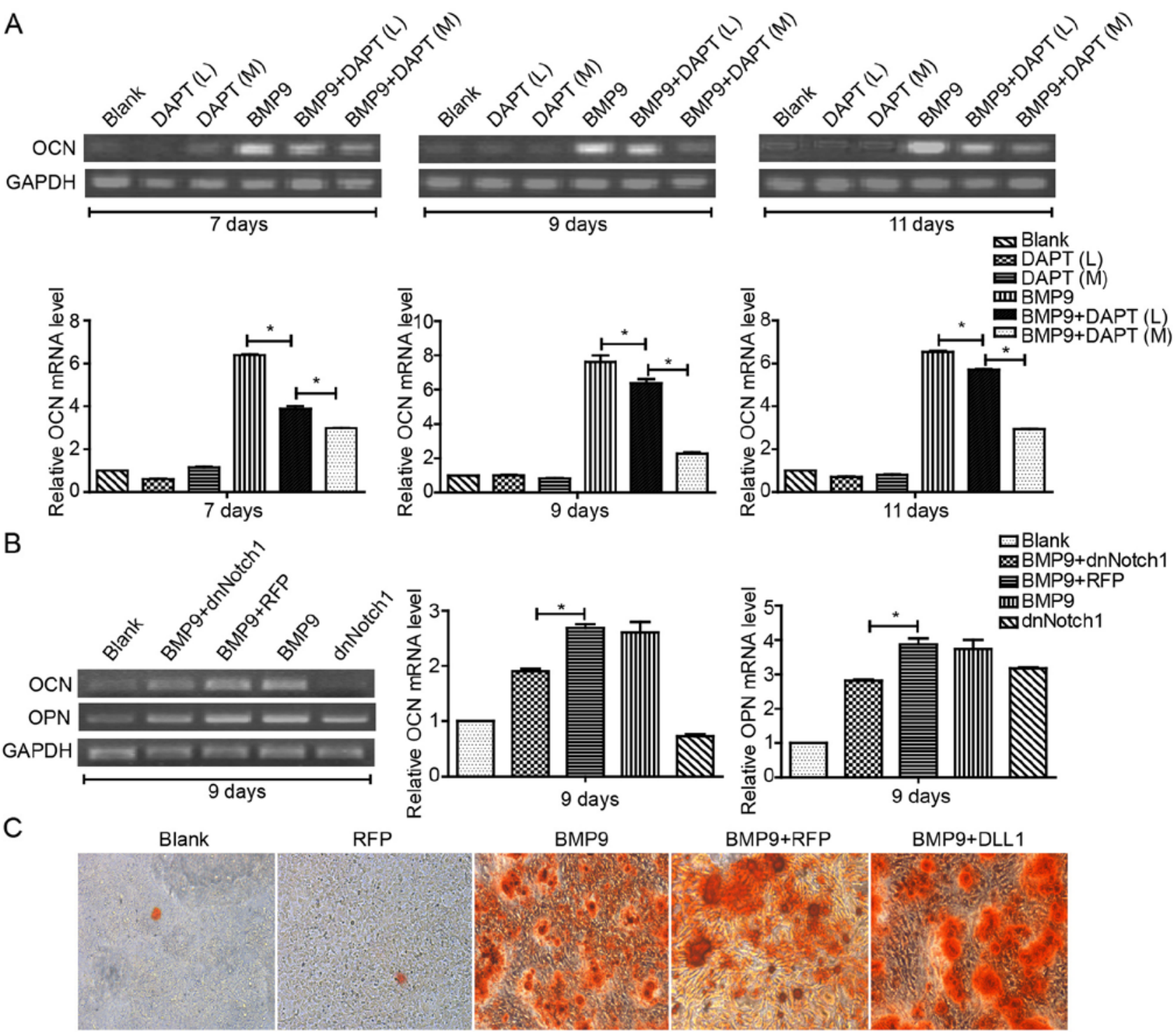

Figure 2. Notch signaling increases BMP9-induced late osteogenic differentiation of MSCs. (A) C2C12 cells were treated with different concentrations of DAPT $(\mathrm{M}=10 \mu \mathrm{M}$, and $\mathrm{H}=15 \mu \mathrm{M}$, respectively) in the presence of BMP9-CM, and the gene expression of OCN was determined by semi-quantitative RT-PCR at 7,9 and 11 day(s) post-treatment and quantification by densitometry. (B) MEFs were exposed to Ad-dnNotch1 in the presence of BMP9-CM, and the gene expression levels of OPN and OCN were determined by semi-quantitative RT-PCR at 9 day(s) post-treatment and quantification by densitometry. (C) MEFs were infected with Ad-DLL1 in the presence of BMP9-CM, and matrix mineralization was assessed at 11 day(s) post-treatment by Alizarin Red S staining assay. Magnification, $\mathrm{x} 100 .{ }^{~} \mathrm{P}<0.05$. BMP, bone morphogenetic protein; BMP9-CM, BMP9-conditioned media; OCN, osteocalcin; MEFs, mouse embryo fibroblasts; dnNotch1, dominant-negative mutant of Notch1; OPN, osteopontin; DLL, Delta-like.

Effects of Notch signaling on BMP9-induced activation of $B M P / S m a d$ signaling. We then explored the possible mechanism behind the effect of Notch signaling on the BMP9-induced osteogenic differentiation of MSCs. BMP/Smad signaling is the classical pathway for BMP9 to induced osteogenic differentiation in MSCs. Thus, we aimed to ascertain whether or not Notch regulates this signaling. In the presence of BMP9-CM, we treated the cells for $36 \mathrm{~h}$ with DAPT, Ad-dnNotch1 or Ad-DLL1, respectively. Western blot analysis showed that DAPT had no obvious effects on total protein level of Smad1/5/8, but decreased the phosphorylation level of Smad1/5/8 in the C2C12 cells (Fig. 4A). Similar results were found in MEFs treated with Ad-BMP9 and Ad-dnNotch1 (Fig. 4A). Conversely, Ad-DLL1 was found to enhance the phosphorylation level of Smad1/5/8 induced by BMP9 in the C3H10T1/2 and $\mathrm{C} 2 \mathrm{C} 12$ cells and MEFs (Fig. 4B). Using the BMP responsive Smad1/5/8 reporter,
p12xSBE-luc, we found that Ad-DLL1 promoted BMP9-induced reporter activities prominently in the $\mathrm{C} 3 \mathrm{H} 10 \mathrm{~T} 1 / 2$ and $\mathrm{C} 2 \mathrm{C} 12$ cells and MEFs, and Ad-dnNotch1 impaired the BMP9-induced reporter activities (Fig. 4C). Collectively, these results suggested that Notch signaling can enhance the BMP/Smad signaling transduction induced by BMP9 in MSCs.

Effects of Notch signaling on BMP9-induced expression of essential osteogenic factors in MSCs. It has been demonstrated in our previous study that runt-related transcription factor 2 (Runx2), inhibitor of differentiation (Id)1, 2 and 3 are targets of BMP9, and are critical to BMP9-induced osteogenic differentiation in MSCs (40). Type I collagen (Colla1) is the special collagen secreted by osteoblast cells. With RT-PCR analysis, we found that the expression of Runx2 and Colla1 induced by BMP9 was decreased by DAPT in a 

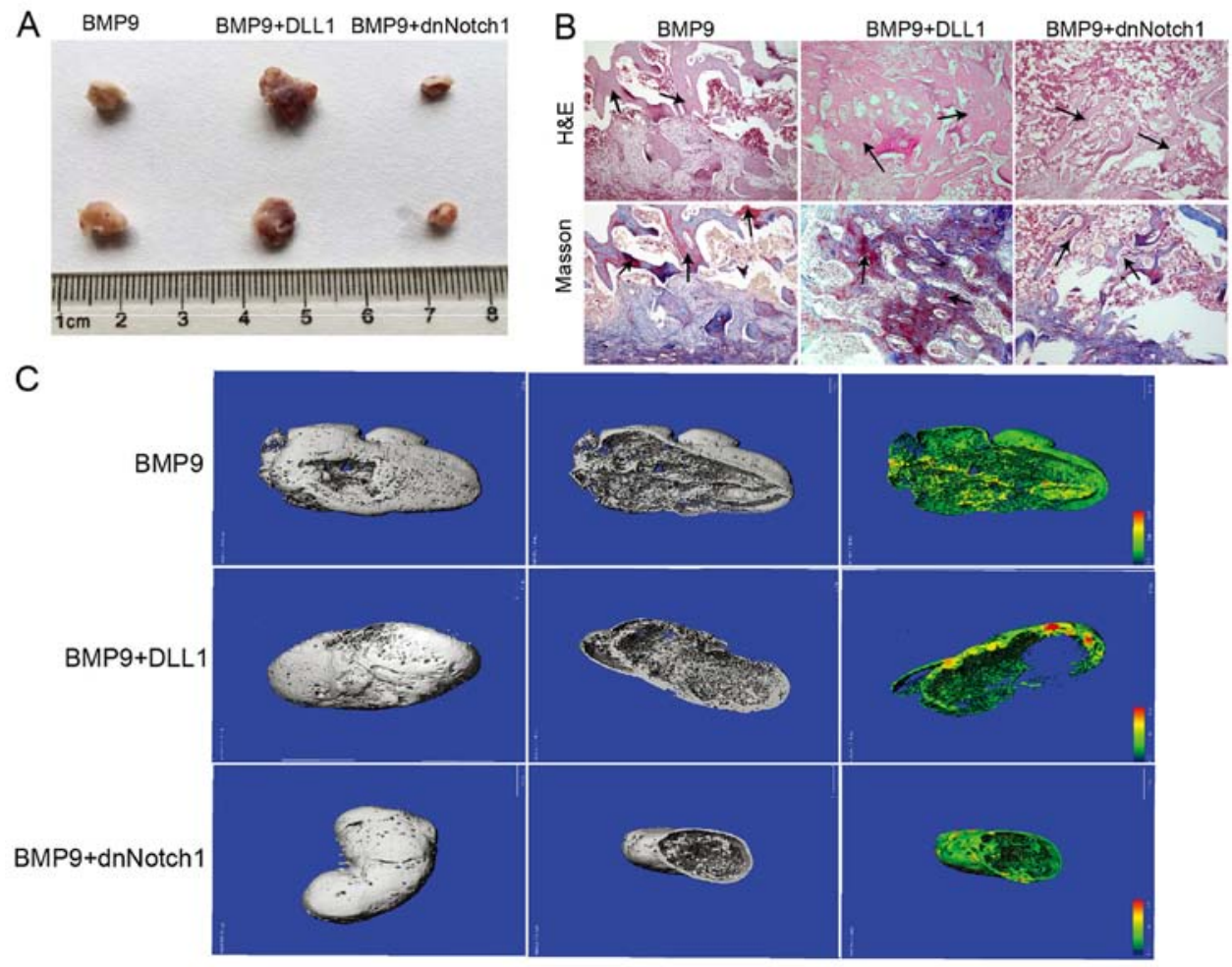

Figure 3. Notch signaling promotes mineralization in BMP9-stimulated MSC implantation in vivo. (A) At 4 week(s), animals were sacrificed, and the ectopic bone masses were retrieved. (B) Histologic analysis of the retrieved samples. The samples were decalcified and paraffin-embedded and sectioned for H\&E and Masson's trichrome staining. Arrows, mineralized matrix. (C) Retrieved samples were subjected to micro-CT imaging analysis, and representative three-dimensional reconstructed images are shown. The color bar indicates the BMD from low (green) to high (red). BMP, bone morphogenetic protein; bone mineral density (BMD).

A
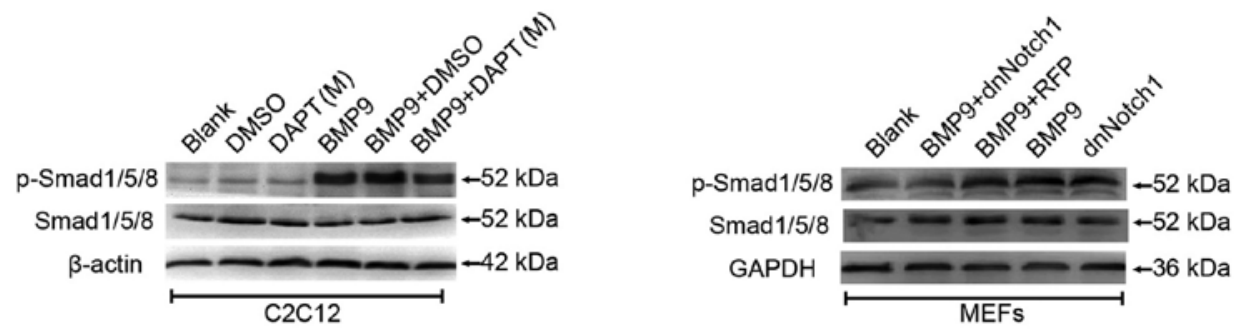

B

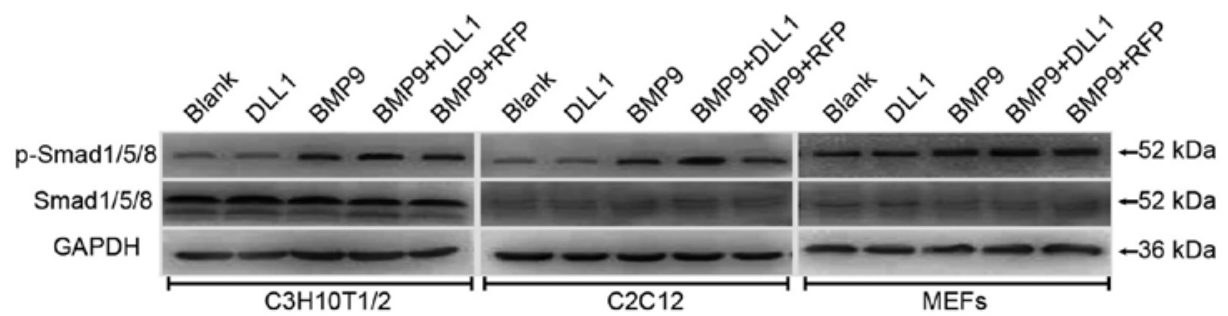

C

2C12
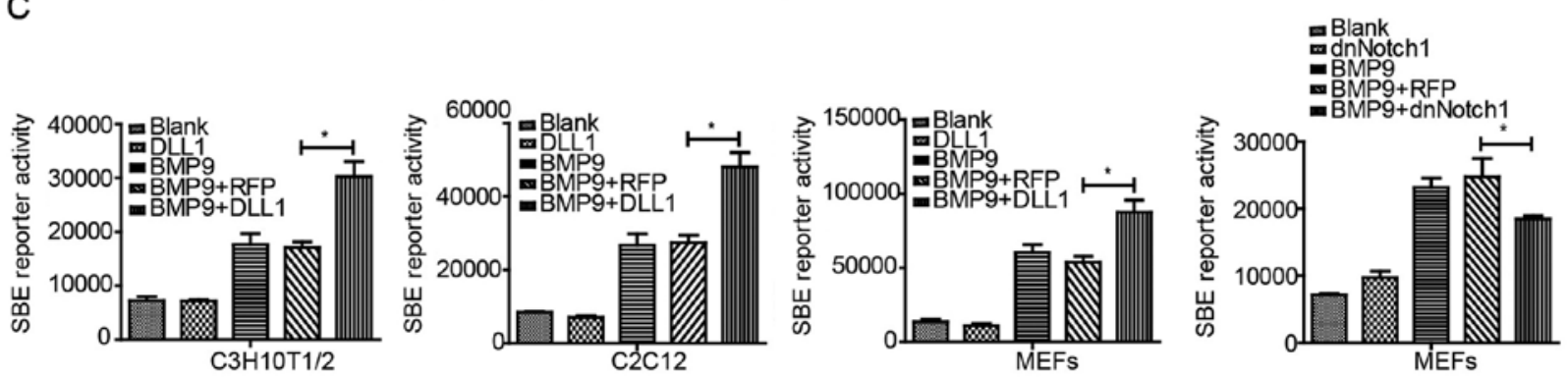

Figure 4. Notch signaling augments the activity of BMP9-induced BMP/Smad signaling. (A and B) C2C12 cells, MEFs and C3H10T1/2 cells were infected with Ad-DLL1 or Ad-dnNotch1 or different concentrations of DAPT (M=10 $\mu \mathrm{M}$, and $\mathrm{H}=15 \mu \mathrm{M}$, respectively) in the presence of BMP9-CM; total amount and phosphorylated forms of Smad1/5/8 were analyzed by western blot analysis. (C) MEFs, C2C12 cells and C3H10T1/2 cells were transfected with p12xSBE-luc and co-infected with Ad-DLL1 or Ad-dnNotch1 in the presence of BMP9-CM; luciferase activity was assessed at $36 \mathrm{~h}$ post-treatment. "P<0.05. BMP, bone morphogenetic protein; MEFs, mouse embryo fibroblasts; DLL, Delta-like; dnNotch1, dominant-negative mutant of Notch1; BMP9-CM, BMP9-conditioned media 
A
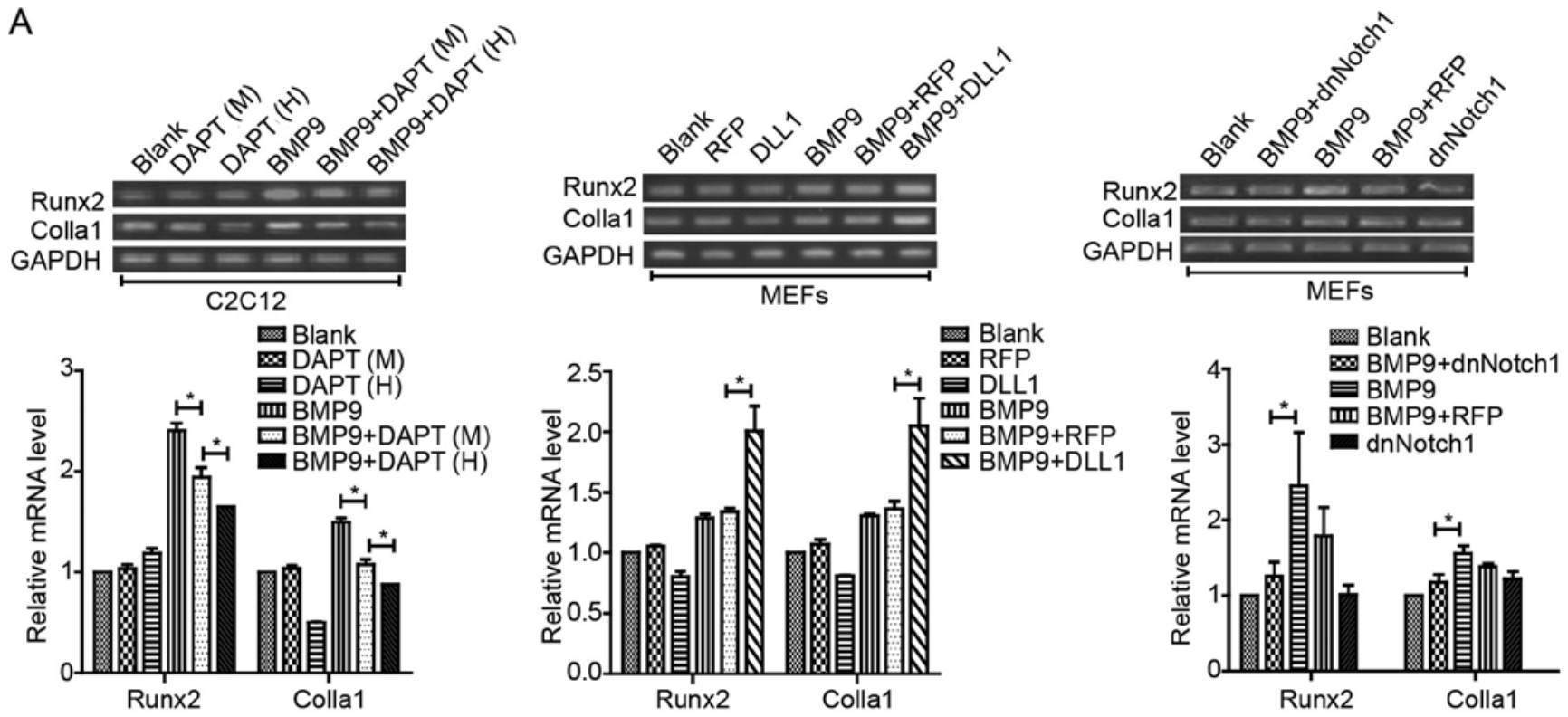

B
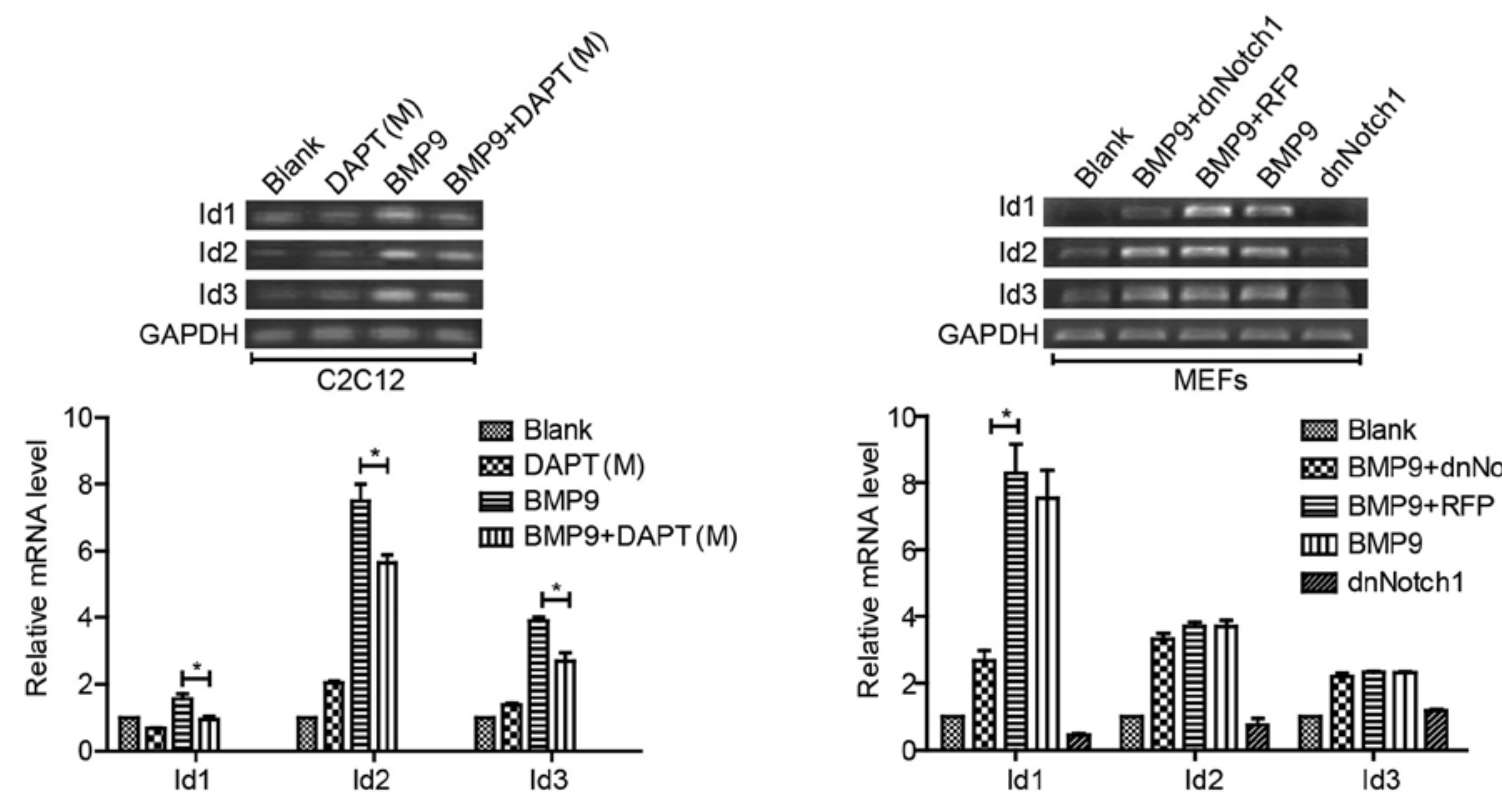

Figure 5. Notch signaling increases the expression of essential osteogenic factors induced by BMP9 in MSCs. (A) MEFs and C2C12 cells were treated with Ad-dnNotch1 or Ad-DLL1 or different concentrations of DAPT ( $\mathrm{M}=10 \mu \mathrm{M}$, and $\mathrm{H}=15 \mu \mathrm{M}$, respectively) in the presence of BMP9-CM. The gene expression of Runx2 and Colla1 was detected by semi-quantitative RT-PCR at indicated time-points and quantification by densitometry. (B) MEFs and C2C12 cells were treated with DAPT $(\mathrm{M}=10 \mu \mathrm{M})$ or Ad-dnNotch1 in the presence of BMP9-CM, and the gene expression levels of Id, Id2, Id3 were detected by semi-quantitative RT-PCR at 24 h post-treatment and quantification by densitometry. "P<0.05. BMP, bone morphogenetic protein; MEFs, mouse embryo fibroblasts; dnNotch1, dominant-negative mutant of Notch1; DLL, Delta-like; BMP9-CM, BMP9-conditioned media; Runx2, runt-related transcription factor 2; Colla1, type I collagen; Id, inhibitor of differentiation.

concentration-dependent manner in $\mathrm{C} 2 \mathrm{C} 12$ cells, and similar results were found in MEFs when treated with Ad-dnNotch1 combined with BMP9-CM. Yet, the BMP9-induced expression levels of Runx2 and Colla1 were increased when treated with Ad-DLL1 combined with BMP9-CM (Fig. 5A). We also found that the expression levels of Id1, Id2 and Id3 were decreased by DAPT in the presence of BMP9, but only Id1 was decreased by Ad-dnNotch1 combined with BMP9-CM treatment in MEFs (Fig. 5B). These results indicated that Notch signaling was able to regulate BMP9-induced essential osteogenic factors, but there may be some differences between different ligands/receptors.
Effects of Notch signaling on the expression of ALK2 induced by BMP9. ALK1 and ALK2 are functional receptors essential for BMP9 osteogenic activity (42). BMP9 can increase the expression of ALK1 and ALK2 in MSCs, which is likely to be a novel clue to demonstrate the molecular mechanism underlying BMP9-induced osteogenic differentiation of MSCs. Therefore, we aimed to ascertain whether or not Notch can affect ALK1 and ALK2. With qPCR, we found that it was ALK2 but not ALK1 that was significantly downregulated by Ad-dnNotch1 combined with BMP9-CM in MEFs (Fig. 6A). Ad-DLL1 promoted the gene expression of ALK2 induced by BMP9 in MEFs, but had no apparent effect on ALK1 gene 


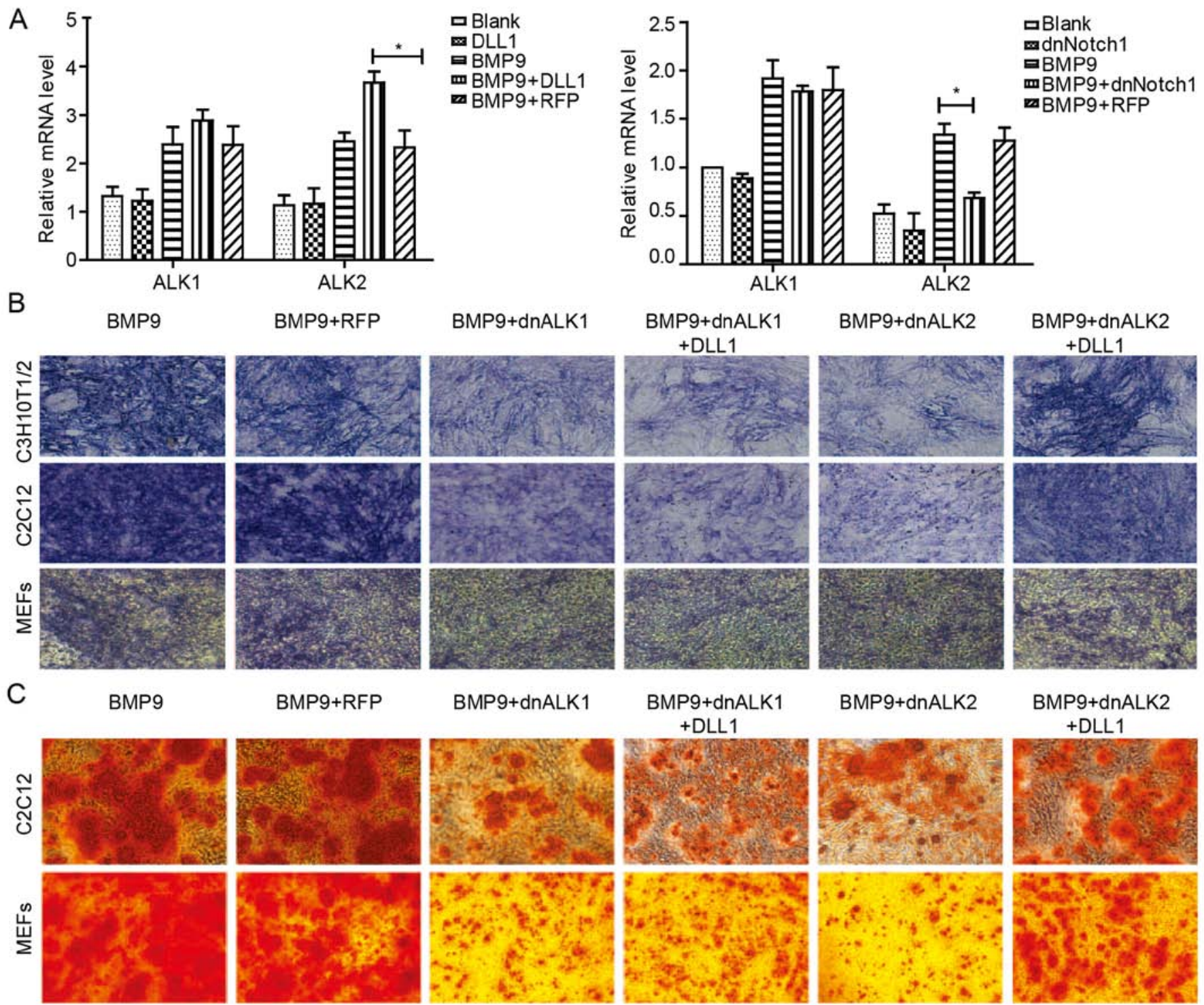

Figure 6. Notch signaling promotes BMP9-induced ALK2 gene expression, and the inhibitory effect of dnALK2 on BMP9-induced osteogenic differentiation is rescued by overexpression of DLL1. (A) MEFs were treated with Ad-DLL1 or Ad-dnNotch1 in the presence of BMP9-CM, and the gene expression of ALK1 and ALK2 was detected by qPCR at 3 day(s) post-treatment. (B) C3H10T1/2 cells, C2C12 cells and MEFs were infected with Ad-DLL1 and/or Ad-dnALK1, Ad-dnALK2, or Ad-RFP for $24 \mathrm{~h}$, and were stimulated with BMP9-CM. ALP activity was assessed by staining assay at 5 day(s) post-treatment. (C) Matrix mineralization was assessed at 9 day(s) post-treatment by Alizarin Red S staining assay. Magnification, $\mathrm{x} 100 .{ }^{\text {"P }}<0.05$. BMP, bone morphogenetic protein; ALK, activin-like kinase; DLL, Delta-like; MEFs, mouse embryo fibroblasts; dnNotch1, dominant-negative mutant of Notch1; BMP9-CM, BMP9-conditioned media; ALP, alkaline phosphatase.

expression (Fig. 6A). In order to ascertain whether Notch signaling augments BMP9-induced osteogenic differentiation by increasing the gene expression of ALK2, we treated cells with Ad-dnALK1 and Ad-dnALK2, respectively, in the presence of BMP9-CM. We noted that BMP9-induced osteogenic differentiation was markedly impaired by Ad-dnALK1 and Ad-dnALK2, and Ad-DLL1 rescued the inhibitory effect of dnALK2, but had no significant effect on dnALK1 (Fig. 6B and C). These results suggested that DLL1/Notch signaling may regulate BMP9-induced osteogenic differentiation of MSCs by partly increasing BMP9-dependent upregulation of ALK2.

Effect of Notch signaling on the proliferation of MSCs during BMP9-induced osteogenic differentiation. Notch signaling is involved in regulating the balance between cell differentiation and stem cell proliferation during the development of numerous tissues. Notch signaling may affect BMP9-induced osteogenic differentiation by regulating the proliferation of MEFs. Using FCM analysis, we found that following treatment withAd-DLL1 combined with BMP9-CM the percentage of MEFs in the $S$ phase was increased compared to the percentage of cells treated with Ad-RFP combined with BMP9-CM. In addition, the percentage of cells in the G0/G1 phase decreased significantly. We also noted that Ad-dnNotch1 decreased the $\mathrm{S}$ phase cell percentage induced by BMP9-CM, but apparently increased the cell percentage in G0/G1 (Fig. 7A and B). Based on these data, Notch may promote the proliferation of MSCs in the presence of BMP9-CM. 


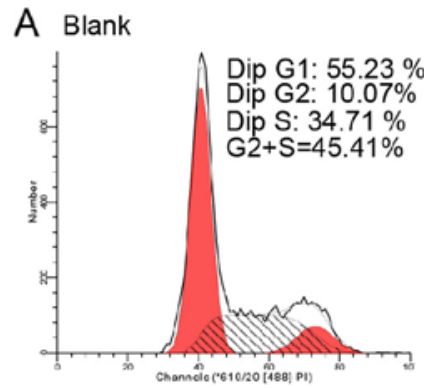

dnNotch1

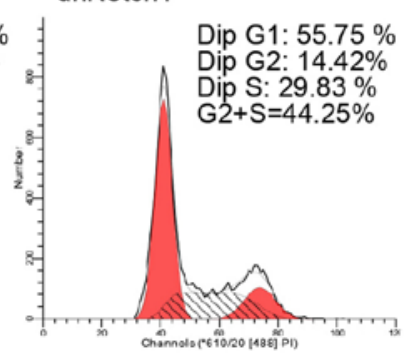

B Blank
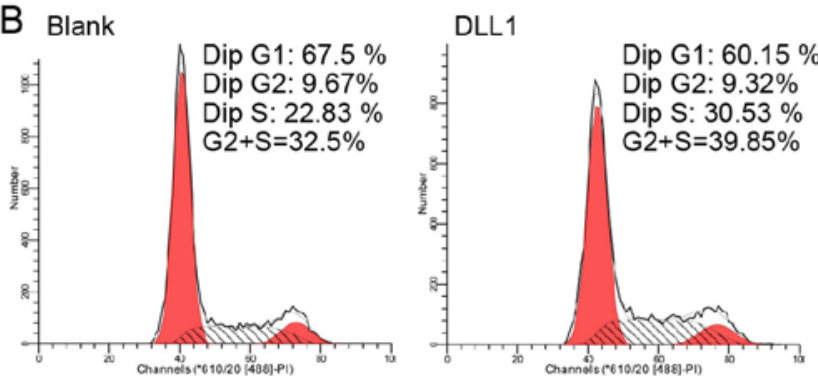

BMP9+RFP

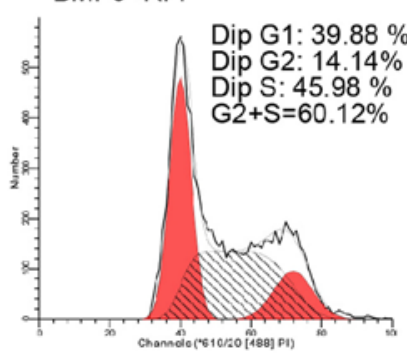

BMP9+RFP

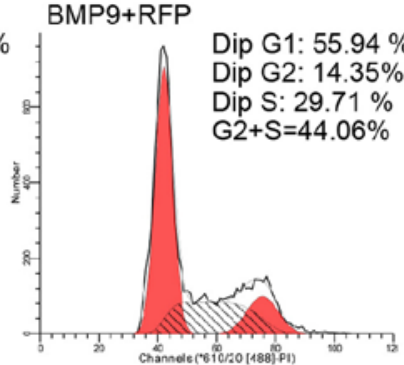

BMP9+dnNotch1

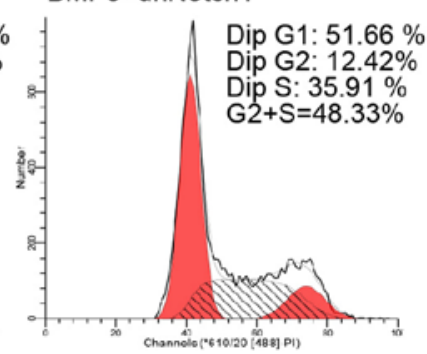

BMP9+DLL1

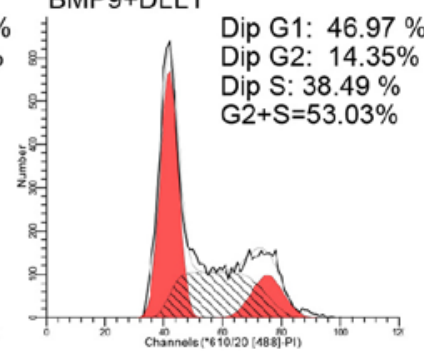

Figure 7. Notch signaling exhibits an apparent effect on proliferation in MEFs during BMP9-induced osteogenic differentiation. (A and B) Cell cycle analysis was detected by FCM in MEFs. MEFs, mouse embryo fibroblasts; BMP, bone morphogenetic protein; FCM, flow cytometry.

\section{Discussion}

In the present study, we investigated the effect of Notch signaling on BMP9-induced osteogenic differentiation in MSCs, and the possible mechanism underlying this process. Our findings suggested that Notch signaling can enhance the activity of BMP9 to induce osteogenic differentiation in MSCs, and this effect may be partly mediated by upregulation of ALK2.

BMP9, also called GDF-2, is one of the least studied BMPs (44). Numerous studies have indicated that BMP9 has pivotal biological functions in the areas of liver fibrosis, iron metabolism, cartilage formation and angiopoiesis, and recent studies have shown that BMP9 is the strongest inducer of osteogenic differentiation, which has been regarded as a potential factor in tissue engineering (45). The studies concerning BMP9-induced osteogenesis mechanism are conducive to its application in bone-related diseases. Previous research has indicated that fibroblast growth factor 2 (FGF2) inhibits BMP9-induced osteogenic differentiation by blocking BMP9-induced Smad signaling and subsequently reducing Smad-dependent upregulation of ALK1 and ALK2 in MSCs (41). Canonical Wnt/ $\beta$-catenin signaling acts synergistically on BMP9-induced osteogenic differentiation (46). p38 and ERK1/2 MAKPs exert opposing effects on BMP9-induced osteogenic differentiation (43). Cox2 is critical for BMP9 to induce osteogenic differentiation in MSCs (39). Hedgehog signaling is involved and plays a regulatory role in the osteogenic differentiation of MSCs induced by BMP9 (40). Yet, little is known concerning the effect of Notch signaling on BMP9-induced osteogenic differentiation. Although the importance of Notch on bone remodeling has been found, its role in bone formation remains uncertain. Some studies have determined that Notch signaling can crosstalk with BMP2 to regulate osteogenesis and skeletal remodeling (47-49). However, the effects of Notch signaling on BMP-induced osteogenesis are incompatible. Delta1/Jagged1-activated
Notch1 enhances BMP2-induced differentiation in MC3T3-E1 and $\mathrm{C} 2 \mathrm{C} 12$ cells (49). Similarly, Notch signaling promotes osteogenic differentiation and mineralization of vascular SMCs by directly activating Msx2 gene transcription via RBP-Jא (50). Other groups have indicated the opposite results that disruption of Notch signaling in the limb skeletogenic mesenchyme markedly increased trabecular bone mass in adolescent mice (51). In any case, Notch signaling plays critical roles in BMP2-regulated osteogenesis and skeletal remodeling. These different results may be associated with the differentiation of cell lines and the methods used to upregulate or downregulate the pathway. On the other hand, these reports also suggest that there may be complex crosstalk between Notch and BMP signaling.

Our mechanistic studies demonstrated that Notch may enhance the osteogenic differentiation of MSCs by augmenting the activity of BMP9/Smad signaling. The activation of $\mathrm{BMP} / \mathrm{Smad}$ signaling is initialized from the binding of BMPs and their receptors (BMPRs). Thus, we aimed to clarify whether BMP9/Smad signal transduction strengthened by Notch is derived from BMPRs. We treated MSCs with Ad-DLL1, Ad-dnNotch and DAPT, respectively. We found that the expression of ALK2 (a type of type I BMP receptor) was markedly increased after upregulation of Notch and decreased when Notch was downregulated. But other BMPRs had no changes. When treated with Ad-dnALK2, BMP9-induced osteogenic differentiation of MSCs was obviously suppressed, but this inhibition was rescued by the presence of Ad-DLL1. These results showed that the effect of Notch on the activation of the BMP9/Smad signaling may be mediated by upregulation of ALK2 in MSCs.

ALK2, also known as activin A receptor type 1 (ACVR1, is a type I receptor which contributes to osteogenic differentiation induced by BMP2, BMP6, BMP7 and BMP9 $(17,52)$. It has been reported that ALK1 and ALK2 are essential for BMP9-induced osteogenic differentiation and ALK2 is required for chondrogenesis during development $(42,53,54)$. Gain-of-function mutation of ALK2 gene is involved in the pathogenesis of fibrodysplasia ossificans progressiva (FOP), 
which is characterized by progressive heterotopic endochondral ossification in muscles and other non-skeletal tissues (55). Thus, ALK2 plays a key role in osteogenic differentiation. Previous studies have revealed that BMP9 upregulates ALK2 expression in MSCs through BMP/Smad signaling (42). Yet, the mechanisms regulating ALK2 expression are still poorly understood. Our data suggested that the expression of ALK2 may be regulated by BMP9 and Notch, but the mechanisms need to be further studied.

It is generally believed that during the process of cell differentiation, cell proliferation is inhibited to some extent. We investigated the proliferation of MSCs during osteoblastogenesis induced by BMP9. Our FCM data revealed that Notch enhanced the proliferation of MSCs by decreasing the percentage of cells in the G0/G1 phase, and increasing the percentage of cells in the $S$ phase

In conclusion, we demonstrated that Notch signaling can potentiate the BMP9-induced osteogenic differentiation of MSCs. In regards to the mechanism, we found that this effect may be mediated by upregulation of the expression of ALK2 to enhance the activation the BMP/Smad signaling induced by BMP9.

\section{Acknowledgements}

We thank Dr Tong-Chuan He (University of Chicago Medical Center) for providing the recombinant adenoviruses. This study was supported in part by research grants from the Chongqing Natural Science Foundation (CSTC2012jjA10004 and KJ130305).

\section{References}

1. Hansson EM, Lendahl U and Chapman G: Notch signaling in development and disease. Semin Cancer Biol 14: 320-328, 2004.

2. Zanotti S and Canalis E: Notch and the skeleton. Mol Cell Biol 30: 886-896, 2010.

3. Campbell DP, Chrysostomou E and Doetzlhofer A: Canonical Notch signaling plays an instructive role in auditory supporting cell development. Sci Rep 6: 19484, 2016.

4. Kopan R and Ilagan MX: The canonical Notch signaling pathway: Unfolding the activation mechanism. Cell 137: 216-233, 2009.

5. Colombo M, Galletti S, Garavelli S, Platonova N, Paoli A, Basile A, Taiana E, Neri A and Chiaramonte R: Notch signaling deregulation in multiple myeloma: A rational molecular target. Oncotarget 6: 26826-26840, 2015.

6. Xiao Z, Zhang J, Peng X, Dong Y, Jia L, Li H and Du J: The Notch $\gamma$-secretase inhibitor ameliorates kidney fibrosis via inhibition of TGF- $\beta / \mathrm{Smad} 2 / 3$ signaling pathway activation. Int $\mathbf{J}$ Biochem Cell Biol 55: 65-71, 2014.

7. Artavanis-Tsakonas S, Matsuno K and Fortini ME: Notch signaling. Science 268: 225-232, 1995.

8. Ehebauer M, Hayward P and Arias AM: Notch, a universal arbiter of cell fate decisions. Science 314: 1414-1415, 2006.

9. Bi P and Kuang S: Notch signaling as a novel regulator of metabolism. Trends Endocrinol Metab 26: 248-255, 2015.

10. Colombo M, Thümmler K, Mirandola L, Garavelli S, Todoerti K, Apicella L, Lazzari E, Lancellotti M, Platonova N, Akbar M, et al: Notch signaling drives multiple myeloma induced osteoclastogenesis. Oncotarget 5: 10393-10406, 2014.

11. Kushwah R, Guezguez B, Lee JB, Hopkins CI and Bhatia M: Pleiotropic roles of Notch signaling in normal, malignant, and developmental hematopoiesis in the human. EMBO Rep 15: 1128-1138, 2014

12. Wahi K, Bochter MS and Cole SE: The many roles of Notch signaling during vertebrate somitogenesis. Semin Cell Dev Biol 49: 68-75, 2016.
13. Tao J, Chen S, Yang T, Dawson B, Munivez E, Bertin T and Lee B: Osteosclerosis owing to Notch gain of function is solely Rbpj-dependent. J Bone Miner Res 25: 2175-2183, 2010.

14. Dong Y, Jesse AM, Kohn A, Gunnell LM, Honjo T, Zuscik MJ, O'Keefe RJ and Hilton MJ: RBPjkappa-dependent Notch signaling regulates mesenchymal progenitor cell proliferation and differentiation during skeletal development. Development 137: 1461-1471, 2010.

15. Dong Y, Long T, Wang C, Mirando AJ, Chen J, O'Keefe RJ and Hilton MJ: NOTCH-mediated maintenance and expansion of human bone marrow stromal/stem cells: A technology designed for orthopedic regenerative medicine. Stem Cells Transl Med 3: 1456-1466, 2014.

16. Sánchez-Duffhues G, Hiepen C, Knaus P and Ten Dijke P: Bone morphogenetic protein signaling in bone homeostasis. Bone 80 : 43-59, 2015.

17. Katagiri T and Watabe T: Bone morphogenetic proteins. Cold Spring Harb Perspect Biol 8: 8, 2016.

18. Miyazono K, Maeda S and Imamura T: BMP receptor signaling: Transcriptional targets, regulation of signals, and signaling cross-talk. Cytokine Growth Factor Rev 16: 251-263, 2005.

19. Brazil DP, Church RH, Surae S, Godson C and Martin F: BMP signalling: Agony and antagony in the family. Trends Cell Biol 25: 249-264, 2015.

20. Sieber C, Kopf J, Hiepen C and Knaus P: Recent advances in BMP receptor signaling. Cytokine Growth Factor Rev 20: 343-355, 2009.

21. Hogan BL: Bone morphogenetic proteins: Multifunctional regulators of vertebrate development. Genes Dev 10: 1580-1594, 1996.

22. Chen G, Deng $C$ and Li YP: TGF- $\beta$ and BMP signaling in osteoblast differentiation and bone formation. Int J Biol Sci 8: 272-288, 2012.

23. Peng Y, Kang Q, Cheng H, Li X, Sun MH, Jiang W, Luu HH, Park JY, Haydon RC and He TC: Transcriptional characterization of bone morphogenetic proteins (BMPs)-mediated osteogenic signaling. J Cell Biochem 90: 1149-1165, 2003.

24. Schmidt-Bleek K, Willie BM, Schwabe P, Seemann P and Duda GN: BMPs in bone regeneration: Less is more effective, a paradigm-shift. Cytokine Growth Factor Rev 27: 141-148, 2016.

25. Beederman M, Lamplot JD, Nan G, Wang J, Liu X, Yin L, Li R, Shui W, Zhang H, Kim SH, et al: BMP signaling in mesenchymal stem cell differentiation and bone formation. J Biomed Sci Eng 6: 32-52, 2013.

26. Poon B, Kha T, Tran S and Dass CR: Bone morphogenetic protein-2 and bone therapy: Successes and pitfalls. J Pharm Pharmacol 68: 139-147, 2016.

27. Kang Q, Sun MH, Cheng H, Peng Y, Montag AG, Deyrup AT, Jiang W, Luu HH, Luo J, Szatkowski JP, et al: Characterization of the distinct orthotopic bone-forming activity of 14 BMPs using recombinant adenovirus-mediated gene delivery. Gene Ther 11: 1312-1320, 2004.

28. Luu HH, Song WX, Luo X, Manning D, Luo J, Deng ZL, Sharff KA, Montag AG, Haydon RC and He TC: Distinct roles of bone morphogenetic proteins in osteogenic differentiation of mesenchymal stem cells. J Orthop Res 25: 665-677, 2007.

29. Cheng H, Jiang W, Phillips FM, Haydon RC, Peng Y, Zhou L, Luu HH, An N, Breyer B, Vanichakarn P, et al: Osteogenic activity of the fourteen types of human bone morphogenetic proteins (BMPs). J Bone Joint Surg Am 85-A: 1544-1552, 2003.

30. Bi J and Ge S: Potential roles of BMP9 in liver fibrosis. Int J Mol Sci 15: 20656-20667, 2014.

31. Mi LZ, Brown CT, Gao Y, Tian Y,Le VQ, Walz T and SpringerTA: Structure of bone morphogenetic protein 9 procomplex. Proc Natl Acad Sci USA 112: 3710-3715, 2015.

32. Hu N, Jiang D, Huang E, Liu X, Li R, Liang X, Kim SH, Chen X, Gao JL, Zhang H, et al: BMP9-regulated angiogenic signaling plays an important role in the osteogenic differentiation of mesenchymal progenitor cells. J Cell Sci 126: 532-541, 2013.

33. Song JJ, Celeste AJ, Kong FM, Jirtle RL, Rosen V and Thies RS: Bone morphogenetic protein-9 binds to liver cells and stimulates proliferation. Endocrinology 136: 4293-4297, 1995.

34. Dahlqvist C, Blokzijl A, Chapman G, Falk A, Dannaeus K, Ibâñez CF and Lendahl U: Functional Notch signaling is required for BMP4-induced inhibition of myogenic differentiation. Development 130: 6089-6099, 2003.

35. Viale-Bouroncle S, Gosau M and Morsczeck C: NOTCH1 signaling regulates the BMP2/DLX-3 directed osteogenic differentiation of dental follicle cells. Biochem Biophys Res Commun 443: 500-504, 2014. 
36. Shin M, Nagai $\mathrm{H}$ and Sheng G: Notch mediates Wnt and BMP signals in the early separation of smooth muscle progenitors and blood/endothelial common progenitors. Development 136: 595-603, 2009

37. Guo $X$ and Wang XF: Signaling cross-talk between TGF- $3 / B M P$ and other pathways. Cell Res 19: 71-88, 2009.

38. SartoriR, Gregorevic P and Sandri M: TGFbeta and BMP signaling in skeletal muscle: Potential significance for muscle-related disease. Trends Endocrinol Metab 25: 464-471, 2014.

39. Wang JH, Liu YZ, Yin LJ, Chen L, Huang J, Liu Y, Zhang RX, Zhou LY, Yang QJ, Luo JY, et al: BMP9 and COX-2 form an important regulatory loop in BMP9-induced osteogenic differentiation of mesenchymal stem cells. Bone 57: 311-321, 2013.

40. Li L, Dong Q, Wang Y, Feng Q, Zhou P, Ou X, Meng Q, He T and Luo J: Hedgehog signaling is involved in the BMP9-induced osteogenic differentiation of mesenchymal stem cells. Int J Mol Med 35: 1641-1650, 2015.

41. Song T, Wang W, Xu J, Zhao D, Dong Q, Li L, Yang X, Duan X, Liang Y, Xiao Y, et al: Fibroblast growth factor 2 inhibits bone morphogenetic protein 9-induced osteogenic differentiation of mesenchymal stem cells by repressing Smads signaling and subsequently reducing Smads dependent up-regulation of ALK1 and ALK2. Int J Biochem Cell Biol 45: 1639-1646, 2013.

42. Luo J, Tang M, Huang J, He BC, Gao JL, Chen L, Zuo GW, Zhang W, Luo Q, Shi Q, et al: TGFbeta/BMP type I receptors ALK1 and ALK2 are essential for BMP9-induced osteogenic signaling in mesenchymal stem cells. J Biol Chem 285: 29588-29598, 2010.

43. Zhao Y, Song T, Wang W, Wang J, He J, Wu N, Tang M, He B and Luo J: P38 and ERK1/2 MAPKs act in opposition to regulate BMP9-induced osteogenic differentiation of mesenchymal progenitor cells. PLoS One 7: e43383, 2012.

44. Zhang J, Weng Y, Liu X, Wang J, Zhang W, Kim SH, Zhang H, Li R, Kong Y, Chen X, et al: Endoplasmic reticulum (ER) stress inducible factor cysteine-rich with EGF-like domains 2 (Creld2) is an important mediator of BMP9-regulated osteogenic differentiation of mesenchymal stem cells. PLoS One 8: e73086, 2013.

45. Luther G, Wagner ER, Zhu G, Kang Q, Luo Q, Lamplot J, Bi Y, Luo X, Luo J, Teven C, et al: BMP-9 induced osteogenic differentiation of mesenchymal stem cells: Molecular mechanism and therapeutic potential. Curr Gene Ther 11: 229-240, 2011.

46. Zhang H, Wang J, Deng F, Huang E, Yan Z, Wang Z, Deng Y, Zhang Q, Zhang Z, Ye J, et al: Canonical Wnt signaling acts synergistically on BMP9-induced osteo/odontoblastic differentiation of stem cells of dental apical papilla (SCAPs). Biomaterials 39: $145-154,2015$.
47. Shimizu T, TanakaT,Iso T, MatsuiH,Ooyama Y,Kawai-Kowase K, Arai M and Kurabayashi M: Notch signaling pathway enhances bone morphogenetic protein 2 (BMP2) responsiveness of Msx2 gene to induce osteogenic differentiation and mineralization of vascular smooth muscle cells. J Biol Chem 286: 19138-19148, 2011.

48. de Jong DS, Steegenga WT, Hendriks JM, van Zoelen EJ, Olijve W and Dechering KJ: Regulation of Notch signaling genes during BMP2-induced differentiation of osteoblast precursor cells. Biochem Biophys Res Commun 320: 100-107, 2004.

49. Nobta M, Tsukazaki T, Shibata Y, Xin C, Moriishi T, Sakano S, Shindo $\mathrm{H}$ and Yamaguchi A: Critical regulation of bone morphogenetic protein-induced osteoblastic differentiation by Delta1/Jagged1-activated Notch1 signaling. J Biol Chem 280: 15842-15848, 2005.

50. Shimizu T, Tanaka T, Iso T, Doi H, Sato H, Kawai-Kowase K, Arai M and Kurabayashi M: Notch signaling induces osteogenic differentiation and mineralization of vascular smooth muscle cells: Role of Msx 2 gene induction via Notch-RBP-Jk signaling. Arterioscler Thromb Vasc Biol 29: 1104-1111, 2009.

51. Hilton MJ, Tu X, Wu X, Bai S, Zhao H, Kobayashi T, Kronenberg HM, Teitelbaum SL, Ross FP, Kopan R, et al: Notch signaling maintains bone marrow mesenchymal progenitors by suppressing osteoblast differentiation. Nat Med 14: 306-314, 2008.

52. Miyazono K, Kamiya Y and Morikawa M: Bone morphogenetic protein receptors and signal transduction. J Biochem 147: 35-51, 2010.

53. Culbert AL, Chakkalakal SA, Theosmy EG, Brennan TA, Kaplan FS and Shore EM: Alk2 regulates early chondrogenic fate in fibrodysplasia ossificans progressiva heterotopic endochondral ossification. Stem Cells 32: 1289-1300, 2014.

54. Zhang D, Schwarz EM, Rosier RN, Zuscik MJ, Puzas JE and O'Keefe RJ: ALK2 functions as a BMP type I receptor and induces Indian hedgehog in chondrocytes during skeletal development. J Bone Miner Res 18: 1593-1604, 2003.

55. Katagiri T: A door opens for fibrodysplasia ossificans progressiva. Trends Biochem Sci 41: 119-121, 2016. 